\title{
The eGovernment Services Delivery of the Italian Municipalities
}

\author{
Davide Arduini ${ }^{1}$, Antonello Zanfei ${ }^{1}$, Mario Denni ${ }^{2}$, and Gerolamo Giungato ${ }^{3}$ \\ ${ }^{1}$ Department of Economics, Society and Politics, \\ University of Urbino "Carlo Bo", Urbino, Italy \\ \{davide.arduini, antonello.zanfei\} @uniurb.it \\ ${ }^{2}$ Italian Competition Authority, Rome, Italy \\ mario.denni@agcm. it \\ ${ }^{3}$ Italian National Institute of Statistics, Rome, Italy \\ giungato@istat.it
}

\begin{abstract}
This paper focuses on factors associated with the development of egovernment services by local public administrations (PAs) in Italy. Using data from 1,176 municipalities in 2005, we show that the combination of internal competencies and context-specific factors is different when explaining decisions to start e-government activities vs. the intensity of such activities. Local PAs involved in e-government are larger, carry out more in-house ICT activities and are more likely to have intra-net infrastructures than PAs offering no digitized services. They are also located in regions having large shares of firms using or producing ICTs, where many other municipalities offer digitized services, and where population density is low. The range and quality of e-gov services increase with their stock of ICT competencies, their efforts to train workers, and their ability to organise interfaces with end-users. Moreover, the range and quality of services is correlated with the broadband infrastructure development of regions.
\end{abstract}

Keywords: Innovation system, Dynamic capabilities, Technology adoption, Electronic government, Innovation in services, Two-part model.

\section{Introduction}

In advanced economies the public sector has been under pressure to increase transparency in administrative procedures and decision making processes as well as increase the efficiency of its services to citizens and business enterprises. These pressures are the result of a combination of factors, including increasing competition in political arenas, institutional changes and technical progress. The use of digital technologies at all levels of Public Administrations (PAs) and the development of "egovernment" services are a key aspect of this transformation [1]. Studies on digital technology adoption and on ICT based services supplied by public organisations, however, reveal the existence of a considerable heterogeneity across EU countries and regions [2, 3]. In other words, not all PAs are equally prone to involvement in egovernment nor are they equally active in this field. Using data on 1,176 Italian 
municipalities in year 2005, this paper contributes to our understanding of this diversity. More precisely we analyse the factors that are associated with PA decisions on whether and how to become involved in e-government activities.

The analysis carried out in this paper can be cast in a general framework that explains innovation as the result of a process wherein the competencies of innovating entities co-evolve with the technological, institutional and economic environment in which they are active [4]. In this case, we shall focus on a specific category of innovators, namely local-level public administrative bodies, which we shall call "municipalities" from now on. We shall use the provision of digitalised front office services to the citizens, firms and other institutions (e-government) as a measure, though partial, of municipality innovation. Furthermore, we consider the relevant technological, institutional and economic context for innovation to be largely represented by the "regions" in which municipalities are located. While the choice of territorial aggregation is always arbitrary, we thought it sensible and feasible in terms of data availability to utilise the Eurostat NUTS2 level of analysis for Italy, which corresponds to the 21 sub-national regions that were institutionalised in 1970 following a constitutional provision of 1948. In this general framework, we shall show that different competencies and contextual factors matter when considering innovation rate between or within municipalities.

The rest of this paper is organised as follows. Section 2 draws together different streams of literature to single out the key factors that can help explain innovation in public services in general and e-government in particular. Section 3 illustrates our datasets and discusses the empirical strategy we follow. Section 4 examines the results of the econometric exercise carried out on innovative activities of Italian municipalities. Section 5 concludes.

\section{Background Literature on Innovation and Implications for Public Services}

Innovation in services has attracted increasing, albeit still limited, attention in economic literature $[5,6,7]$. As particularly stressed by the evolutionary approach, our understanding of innovation can greatly benefit from the analysis of competencies of firms and institutions. This stream of literature views innovators as depositories of largely tacit knowledge incorporated in such firm-specific assets as routines, skills, technical and organisational capabilities [8,9]. Such assets, normally identified with the comprehensive term "competencies", are the result of conscious efforts to invest in training of human capital and in institutionalised R\&D. Moreover, competencies originate from learning processes associated with production, the use of technology and the interaction with external parties (other producers, users, and institutions) which are themselves depositories of knowledge assets.

To explain better the introduction of innovation in general, and of e-government services as a special case of innovation in services, one also needs to acknowledge the importance of context specific factors. There is a general consensus on the role played by demand conditions as fundamental drivers for innovation. The hypothesis that extensive and growing demand stimulates innovation was originally proposed by Schmookler $[10,11]$ and tested at different levels of analysis with a focus on the 
manufacturing industry $[12,13,14]$. Most contributions on innovation in services emphasise the importance of demand determinants of innovative activities [15, 16] although there are few empirical studies concerning this issue. In the public sector case, attention has been given to the role of governmental bodies in public procurement of advanced technology, hence as actors on the demand side affecting innovation carried out by supplier sectors $[17,18]$.

Apart from the characteristics of demand, innovation is affected by a number of other context specific factors and by the complex networks of relationships among the different actors involved in innovative activities [19, 20]. Important interdependencies can be observed between all components in innovation systems, whether the systems are defined at the national, regional or sectoral level.

The interactive and systemic nature of innovation is mediated by spatial factors, such as geographic proximity and localised knowledge accumulation. Emulation processes across innovators, user-producer interactions, knowledge exchanges and involuntary information leakages are favoured by close interaction and day-to-day contact between actors involved. There is significant evidence of inter-regional variations in the generation and adoption of new technology, revealing that innovation tends to be geographically bounded $[21,22,23]$.

\section{Data Sources and Empirical Strategy}

In this section we illustrate the data and methods we utilize to examine the factors affecting the innovative activities of Italian PAs. As stated in the introduction, our unit of analysis is based on local PAs (municipalities), and we use their involvement in the provision of digitalized front office services (e-government) as the dependent variable in our econometric exercise. We expect different factors at the municipality and contextual levels to be associated with the introduction of e-government services. These factors were selected from the existing literature on innovation processes, as in Section 2. Let us first illustrate our data sources and then discuss how these are utilized for analytical purposes.

\subsection{Data}

Our empirical tests are based on data at both municipality and contextual (mainly regional) levels. For one variable only data is collected at the level of the Italian provinces.

For municipality level variables, data are obtained by merging two different surveys. One is the survey conducted by Italy's National Bureau of Statistics (Istat) in 2006 on the usage of ICT in 3,323 Italian local public administrations. It collects information on the diffusion and use of ICT in the local public administrations. The other is the survey carried out in 2006 by the National Centre for the Information Technology in the Public Administration (Cnipa) on the official websites of 1,825 Italian municipalities. It includes information on some 266 on-line services provided by the municipalities. The intersection of the two datasets yields cross-sectional information referring to 1,176 municipalities in 2005 , providing the final sample size used in the econometric exercise. 
The eGovernment Services Delivery of the Italian Municipalities

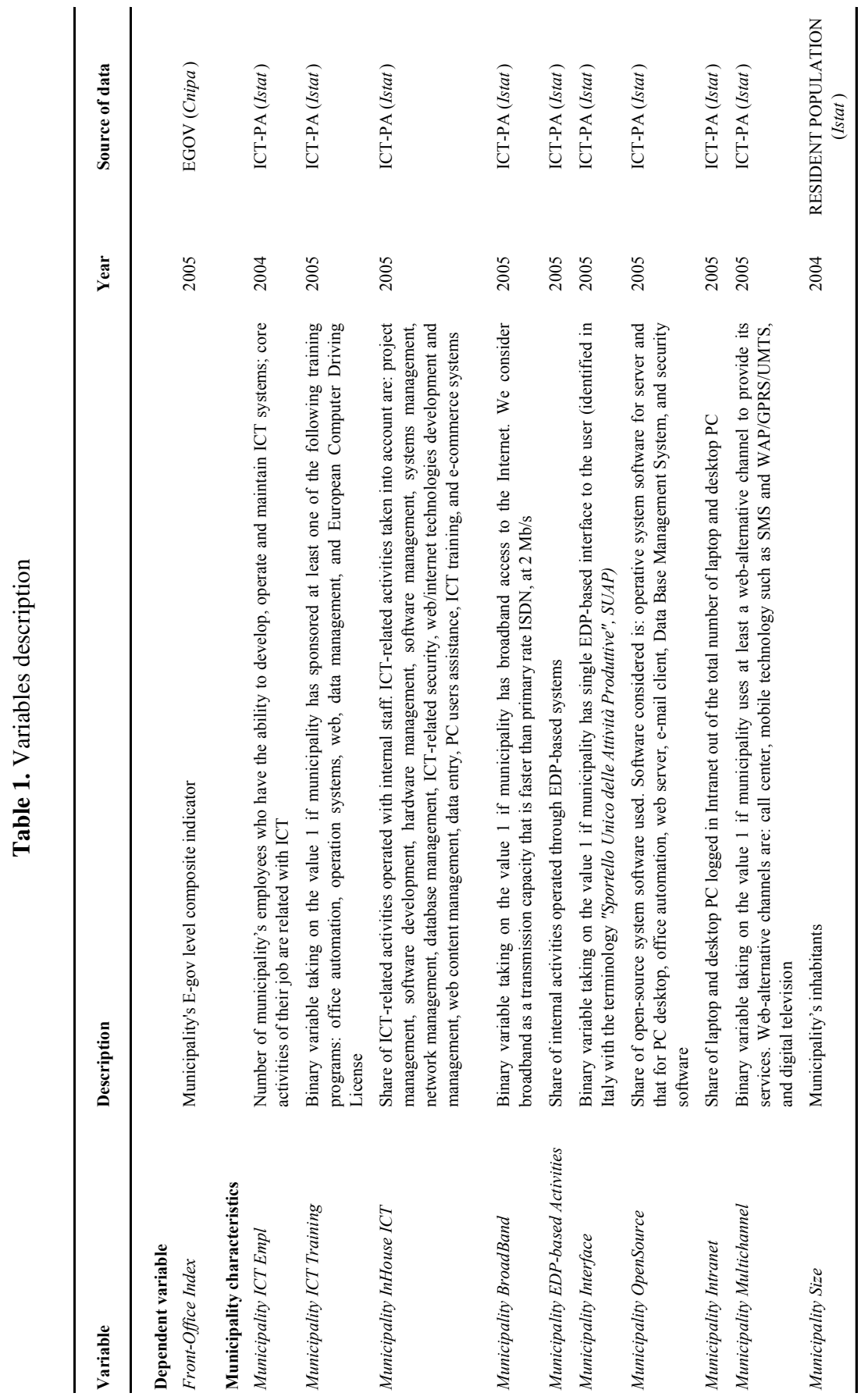




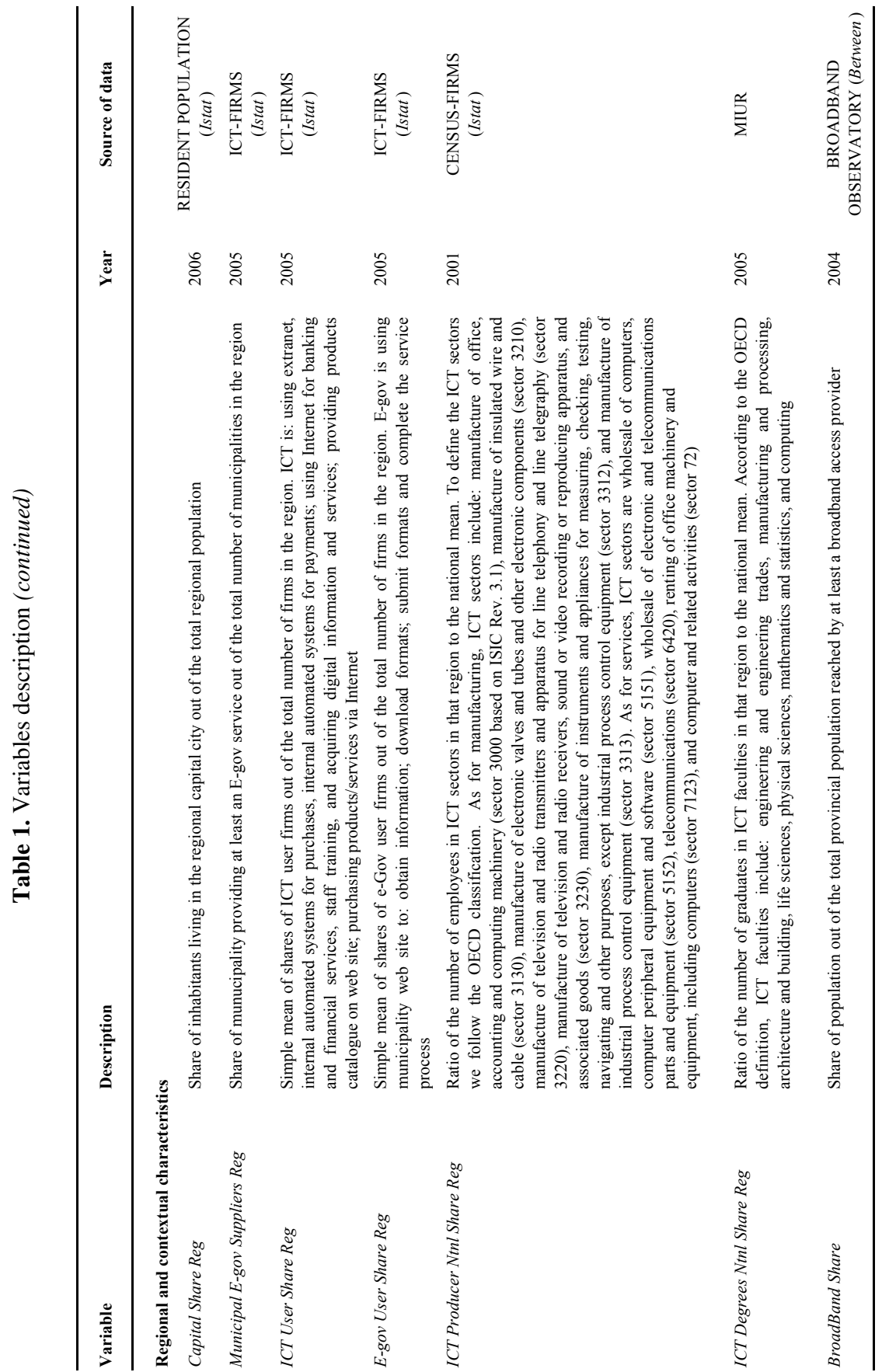




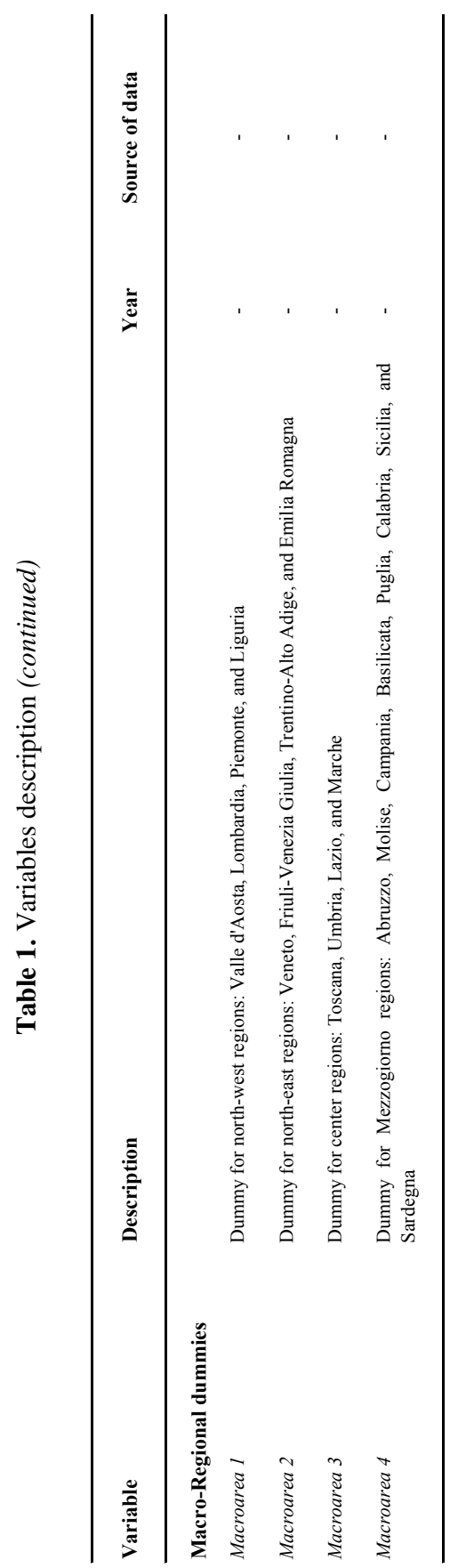

Data on several regional level variables have then been drawn from different surveys. One is the 2005 survey on the usage of ICT in Italian firms with 10 employees or more. Data on employees in ICT sectors come from the $8^{\text {th }}$ General 
Industry and Services Census carried out in 2001. Data on inhabitants at the municipality level are taken from the Istat project "Demography in Figures". The MIUR (Italian Ministry of University and Research) survey on the tertiary education provides data on the number of graduates in ICT disciplines as a measure of human capital endowments in fields relating to e-government. For all the variables where information is available at regional level, the same value is assigned to every municipality belonging to the same region. As a result, we have no intra-regional variance and only in inter-regional variation at this level of analysis.

Finally, information on the diffusion of broadband infrastructure and services are taken from the Broadband Observatory. These are the only data to which we have access available at the provincial level. Table 1 provides a brief description of all the explanatory variables considered in the empirical application and their source.

\subsection{The Dependent Variable: The Front Office Index (FOI)}

The dependent variable in our econometric exercise is a composite indicator measuring the availability and the level of interactiveness of on-line services for each administration. Information on these two dimensions come from the Cnipa dataset. Examining the official websites of 1825 municipalities, Cnipa singles out 266 different on-line services. The same service can be recorded for more than one municipality. This results in an initial dataset of 21,337 observations. For each of them, using a taxonomy introduced by Capgemini [24, 25], by means of four dichotomic variables $D i$, the dataset indicates whether or not there are specific characteristics that each reflect a different degree of interactiveness in on-line services:

- the possibility of downloading administrative forms necessary to receive the service (indicated as $D_{1}$ );

- the possibility of exchanging interactive information about the service, such as asking specific questions and obtaining answers $\left(D_{2}\right)$;

- the presence of an authentication procedure through which the user can be identified and given a personal account as a means to enhance security $\left(D_{3}\right)$;

- finally, the possibility of carrying out the whole transaction process on-line $\left(D_{4}\right)$. This represents the most comprehensive level that can be provided for an on-line service.

Note that each service may show none, some, or all of these features.

For analytical purposes, we followed a two-step procedure. First, we employ Multiple Correspondence Analysis (MCA) to associate four binary variables to the 21,337 on-line services observed, so as to compute a weight for each of the four features. At the end of the first step, we have a score for each of the 21,337 entries in the dataset reflecting the "intensity" of the on-line service in terms of quantity (given by the $0 / 1 D i$ variables) and level (given by the weight associated to each $D i$ variable) of actions it performs. For a given on-line service, the score is higher the higher the number of characteristics that service exhibits as well as the higher the degree of interactiveness of these characteristics. Second, we compute a final score for each municipality (the base unit of our analysis) by adding the scores received by all the services provided through its 
official website. This is our Front Office Index (FOI). It is a positive function of both the number of on-line services offered by the administration (the higher the number of on-line services supplied by the municipality, the greater the number of non-null scores computed and hence the higher the FOI associated to the same municipality) and of the "quality" of each of these services (the higher the score of each on-line service provided by the municipality, the higher its final FOI).

\subsection{Independent Variables and Controls}

In light of the selective review of the literature carried out in Section 2, we singled out a set of variables associated with the development of e-government services. These variables can be divided into two broad categories: characteristics of municipalities and contextual (mainly regional) features.

Municipality level variables aim primarily at capturing a large variety of technical and organisational competencies of local administrative bodies. As discussed in sections 2, internal capabilities are considered key drivers of innovation - especially in the evolutionary and resource based views of the firm, which have also been looked at in studies on innovation in service sectors. We distinguish three different sets of internal competencies:

i. Competencies embodied in personnel employed in the municipalities

This is Municipality ICT Empl variable, expressed by the number of employees whose core activities are related to ICT, i.e. software design, computer based operations and maintenance. This variable reflects the actual stock of human capital qualified for the development and provision of digitalised services. Municipality ICT Training is a dummy to identify whether in 2005 municipality $i$ has undertaken specialised training programs in any of 5 technical fields that are relevant for e-government activities. Through this indicator we mean to capture the conscious effort made by the institution to improve the quality of competencies in these areas. Municipality inHouse ICT is expressed as the percentage of ICT related activities carried out in the public organisation by means of internal staff. This variable indicates how capable the organisation is to take care of ICT activities with its own resources, without resorting to specialised external competencies.

\section{ii. $\quad$ Competencies embodied in ICT based devices and instrumentation}

Indicators we used are: Municipality intranet, which measures the percentage of the computers connected to a Local Area Network (LAN); Municipality Broadband, a dummy variable identifying whether or not the municipality's offices have broadband access to the internet; and Municipality OpenSource - that is, the share of open source systems out of the total number of software packages that are in use at the municipality's offices. Since open source software is less established as a technical solution, and its development is by and large based on the interaction among communities of experienced users, we consider its rate of adoption as an indicator of both the innovativeness of systems in use and of the skills of technical personnel employed by the PA. 


\section{iii. Competencies embodied in the PAs' organisation}

To capture this aspect of internal competencies we introduced several indicators of how pervasive ICT is in the overall organisational structure of the municipality. Measures of this type are: Municipality EDP-based activities, expressed as the share of total activities carried out at the municipality level operated using EDPbased systems; Municipality Interface, a dummy identifying whether or not the PA has set up an ICT based system that allows the user to deal with a single on-line administrative interface (the so called "Sportello Unico" in Italian technical jargon); and Municipality Multichannel, a dummy indicating whether or not the PA makes use of diversified channels to provide services, other than face-to-face contacts, that are not based on the web. These alternative channels include inter alia call centers, mobile messaging or interactive cable TV.

As noted, there are important contextual factors which complement internal capabilities as key drivers for innovation in general and in public services in particular. Such "external factors" include:

\section{a. Demand size}

Factors at work on the demand side can be partly captured by our variable Municipality size, which is expressed in terms of the number of inhabitants resident in the territory of the local PA. While this indicator is defined at the municipality level, we suggest that it will help identify the extent of potential demand for e-government services. Consistently with the literature on demand-pull innovation, on demand externalities, and on user-producer interaction which we reviewed in Section 2, we assume Municipality size to be positively associated with e-government development.

\section{b. Demand quality}

To carry out a more detailed analysis of demand factors at a broader level (relative to the municipality level we have just considered), we first use variables that identify specific categories of users, such as ICT User Reg and E-gov User Reg. These are respectively expressed in terms of the percentage of total firms in the region that were reported in 2005 to have adopted ICT-based services in general or e-government services in particular. Unfortunately we do not have lagged data on use of digital services, which would enable us to test whether epidemic patterns of innovation diffusion, induced by previous adoption, can affect the development of e-government. Nevertheless, consistent with systemic approaches to innovation, we can expect that higher shares of companies that use digital services will be positively associated with more extensive and effective user-producer interaction, thus creating greater opportunities for PAs to offer new or improved ICT based services.

As well, we attempt to capture how polarised demand is by identifying the percentage of inhabitants of the region that are concentrated in the capital city (Capital Share Reg). According to the literature on spatial diffusion of innovation, technology adoption tends to be more timely and intensive in locations where larger numbers of potential users are concentrated, especially in the initial stages of technical change [26]. As e-government is in its initial phase of diffusion, one might expect that the higher the share of population in capital cities and in metropolitan areas, the more these services will be concentrated there. 


\section{c. Supply factors}

E-government activities of PAs are affected by the presence of other innovative actors in the same area. Among these actors are the other municipalities offering digitalised services. We capture this factor by means of our variable Municipal E-gov Suppliers $R e g$, expressed as the share of e-government service providers out of the total number of local administrative bodies in the Region. Consistently with systemic as well as spatial innovation approaches, we expect this variable to be positively related to the innovative activities of PAs. In fact, when a high number of innovators are located in a given area, knowledge spillovers will be facilitated and greater incentives are created that push less dynamic institutions to enter the innovation race.

Interdependencies can also be observed between e-government service providers and local ICT producers. We proxy this factor with a separate variable we named ICT Producer Ntnl Share defined as the ratio between the percentage of employees in ICT manufacturing and service sectors out of the total number of employees in the Region, and the same percentage calculated at the national level. This factor is positively associated with the development of e-government services for two main reasons. First, municipalities located in regions with higher shares of ICT producers are in a better position to gain access to relevant technology, including both hardware and software. Second, where public and private markets overlap, as in the case of voice or image transmission over IP, a competitive presence of ICT service providers stimulates municipalities to expand the range of services offered through their city networks.

Another supply-side, context specific factor we wish to account for is the state of communication infrastructure. For this purpose we introduce BroadBand Share, defined as the share of total population of the province in which a municipality is located reached by at least one broadband service provider. We consider wide availability of broadband connections an important condition for the provision of advanced e-government services because it demonstrates high quality infrastructure and might also reflect the existence of (actual and/or potential) competition in the provision of network solutions. Both the technological level and the degree of competition in the provision of network infrastructure are normally associated with higher rates of generation and diffusion of advanced communication services [27].

We further control for the availability of a pool of qualified human capital, a factor particularly emphasised in studies on the generation and diffusion of innovation in ICTs [28]. To capture the role of this factor, we calculate the ratio between the percentage of graduates in ICT disciplines out of total graduates in the Region and the same percentage at the national level (ICT Degrees Ntnl Share Reg). Indeed, this indicator will at the same time reflect the qualitative level of actual and potential workers in ICT manufacturing and service sectors and the competencies of potential users. In both cases the impact on e-government service provision should be positive.

Finally, we also introduce controls for macro-regions. This enables us to account for a number of other observable and unobservable sources of heterogeneity which might affect the provision of e-government services, including income levels, degrees of industrialisation, and sectoral composition of the areas where municipalities are located. 


\subsection{The Econometric Model}

The choice of the econometric model strongly depends on the distribution of the dependent variable, namely the FOI index. Almost 30\% of the observed municipalities do not provide on-line services, i.e. the composite indicator is nil for these units. Thus, our dependent variable is continuous over strictly positive values but takes value zero for a nontrivial fraction of the sample. Given the nature of our dependent variable we argue that a standard censored model would not be appropriate. In fact, municipalities can be thought of as solving an optimization problem, wherein the optimal choice might well be the corner solution, $y=0$. The case of limited dependent variables often arises in econometric analysis, especially when the behaviour of economic agents is being modelled. The traditional approach in dealing with such a problem is the Tobit model. However, this approach requires that the censoring mechanism derives from the same model that generates the outcome variable while in our case the censoring mechanism and outcomes may be more flexibly modelled using separate processes [29]. A two-part model allowing the zeros and non-zeros to be generated by different densities enables us to specify a model for the censoring mechanism and a model for the outcome, conditional on the dependent variable taking positive values. This allows the separation of the estimation of a standard Probit model (using all observations available) from that of an OLS model (using only observations with $F O I>0$ ).

We use a Probit in the first part of our model to analyze the municipality's decision to offer on-line services via its official website. This allows us to explain innovation differences "between municipalities", i.e. which PAs have a propensity to offer egovernment services. The second part is a linear regression model to investigate the determinants of the intensity of e-government development in terms of both quality and quantity of on-line services. Using the terminology introduced earlier, this would allow us to explain innovation differences "within municipalities".

\section{Results}

Table 2 illustrates the results of the econometric exercise we carried out using the data and methodologies discussed in Section 3. The whole set of independent variables illustrated in Section 3.3, was used in both stages of the two part model. The last two columns of Table 2 report the results obtained from the final specification, following the entire selection procedure and controls for heteroskedasticity.

Results from the final specification are by and large consistent with the view we have developed in this paper. As we suggested earlier drawing from different streams of literature, the specific kind of innovation analysed here - namely municipalities' provision of digitalized services - is the result of a combination of internal competencies and of context specific factors. The econometric test suggests that different combinations of such variables are at stake when assessing PA decisions on whether or not to supply digitalized services and when considering the intensity of egovernment activities (number and quality of services provided). In other words, factors associated with variations in innovative activities "between municipalities" are different from factors associated with differences in innovation "within 
Table 2. Estimation results: Probit and OLS

\begin{tabular}{|c|c|c|c|c|c|c|}
\hline \multirow{3}{*}{ Variable } & \multicolumn{2}{|c|}{ Full Models } & \multicolumn{2}{|c|}{ Selected Models } & \multicolumn{2}{|c|}{$\begin{array}{c}\text { Heteroskedastic } \\
\text { Robust Estimates }\end{array}$} \\
\hline & Probit & OLS & Probit & OLS & Probit & OLS \\
\hline & 1 & 2 & 3 & 4 & 5 & 6 \\
\hline \multicolumn{7}{|l|}{ Municipality characteristics } \\
\hline Municipality ICT Empl & $\begin{array}{l}0.062 \\
0,062\end{array}$ & $\begin{array}{l}0.010^{* *} \\
0,004\end{array}$ & & $\begin{array}{l}0.010^{* *} \\
0,004\end{array}$ & & $\begin{array}{l}0.011^{* *} \\
0,005\end{array}$ \\
\hline Municipality ICT Training & $\begin{array}{l}-0,077 \\
0,133\end{array}$ & $\begin{array}{l}0.192 * * \\
0,094\end{array}$ & & $\begin{array}{l}0.196^{* *} \\
0,094\end{array}$ & & $\begin{array}{l}0.177 * * \\
0,090\end{array}$ \\
\hline Municipality InHouse ICT & $\begin{array}{l}0.381 * * \\
0,192\end{array}$ & $\begin{array}{l}1.053 * * * \\
0,140\end{array}$ & $\begin{array}{l}0.447 * * \\
0,178\end{array}$ & $\begin{array}{l}1.058 * * * \\
0,137\end{array}$ & $\begin{array}{l}0.560^{* *} \\
0,219\end{array}$ & $\begin{array}{l}1.063 * * * \\
0,136\end{array}$ \\
\hline Municipality BroadBand & $\begin{array}{l}-0,047 \\
0,109\end{array}$ & $\begin{array}{l}0.255^{* * *} \\
0,084\end{array}$ & & $\begin{array}{l}0.220 * * * \\
0,082\end{array}$ & & $\begin{array}{l}0.251 * * * \\
0,330\end{array}$ \\
\hline Mun. EDP-based Activities & $\begin{array}{l}1.232 * * * \\
0,419\end{array}$ & $\begin{array}{l}0.710^{* *} \\
0,333\end{array}$ & $\begin{array}{l}1.220 * * * \\
0,413\end{array}$ & $\begin{array}{l}0.641 * * \\
0,331\end{array}$ & $\begin{array}{l}1.292 * * * \\
0,456\end{array}$ & $\begin{array}{l}0.720 * * \\
0,331\end{array}$ \\
\hline Municipality Interface & $\begin{array}{l}0,056 \\
0,131\end{array}$ & $\begin{array}{l}0.300 * * * \\
0,091\end{array}$ & & $\begin{array}{l}0.295 * * * \\
0,090\end{array}$ & & $\begin{array}{l}0.281 * * * \\
0,084\end{array}$ \\
\hline Municipality OpenSource & $\begin{array}{l}0,034 \\
0,239\end{array}$ & $\begin{array}{l}0.303 * * \\
0,151\end{array}$ & & $\begin{array}{l}0.341 * * \\
0,149\end{array}$ & & $\begin{array}{l}0.265^{*} \\
0,152\end{array}$ \\
\hline Municipality Intranet & $\begin{array}{l}0.276^{* *} \\
0,123\end{array}$ & $\begin{array}{l}0.175^{*} \\
0,095\end{array}$ & $\begin{array}{l}0.261^{* *} \\
0,119\end{array}$ & $\begin{array}{l}0.195^{* *} \\
0,092\end{array}$ & $\begin{array}{l}0.556^{* *} \\
0,220\end{array}$ & $\begin{array}{l}0,124 \\
0,094\end{array}$ \\
\hline Municipality Multichannel & $\begin{array}{l}0,258 \\
0,200\end{array}$ & $\begin{array}{l}0.312 * * * \\
0,112\end{array}$ & & $\begin{array}{l}0.288^{* *} \\
0,111\end{array}$ & & $\begin{array}{l}0.288^{* * *} \\
0,106\end{array}$ \\
\hline Municipality Size & $\begin{array}{l}0.065^{* * *} \\
0,009\end{array}$ & $\begin{array}{l}0.001^{* *} \\
0,000\end{array}$ & $\begin{array}{l}0.070 * * * \\
0,008\end{array}$ & $\begin{array}{l}0.001 * * \\
0,000\end{array}$ & $\begin{array}{l}0.094 * * * \\
0,015\end{array}$ & $\begin{array}{l}0.001 * * \\
0,000\end{array}$ \\
\hline
\end{tabular}

\section{$\underline{\text { Regional and contextual characteristics }}$}

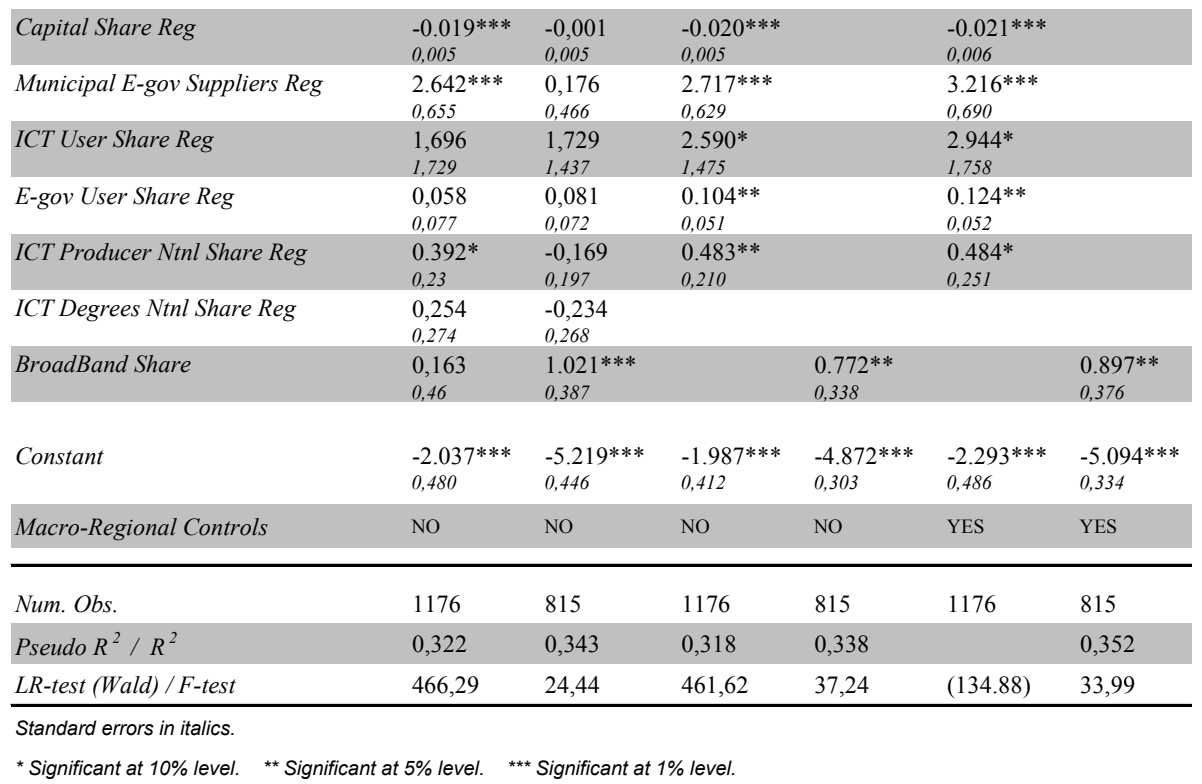

municipalities". Outcomes from the Probit specification in column 5 can be interpreted as "between effects", while those obtained from the OLS part of the model and reported in column 6 illustrate "within effects". 
More specifically, our econometric exercise yields the following sets of results.

First, the environment in which municipalities are active, seems to influence the start up of digitalised services more than their intensity.

Second, among the context specific factors we analysed, demand size and quality stimulate innovative entry into e-government service provision. Demand size at the local level is captured by the number inhabitants resident in the municipality area (Municipality Size). It has a positive and significant impact on differences in innovation between municipalities, reflecting demand pull considerations as well as other bandwagon effects induced by demand externalities and user-producer interactions.

Demand conditions appear to play an even more important role at the regional level. Companies which have already adopted ICT services appear to have the highest impact on the decision of municipalities to get involved in e-government activities (see coefficient of ICT User Share Reg in column 5 of Table 2), suggesting that capable business users are of paramount importance for PAs. Even after controlling for ICT user firms, the impact of E-gov User Share Reg, i.e. the percentage of firms using e-government services, still remains positive and significant in our Probit regression. Although we do not have a data panel to evaluate how previous patterns of adoption affect diffusion, this result is largely consistent with the idea that innovation is favoured by pioneer users.

Third, demand polarisation hampers innovation in public services. This is shown by the negative coefficient of Capital Share Reg in column 5 of Table 2, indicating that a high weight of the region's capital will inhibit innovation elsewhere, especially in the early stages of development of new services.

Fourth, emulation effects, knowledge exchanges, and competitive pressures can be observed on the supply side. The most important factor positively associated with the decision to supply digitalised services appears to be the number of e-government providers in the region (see coefficient of Municipal e-gov supplier Reg in column 5 of Table 2). Emulation factors matter here, especially in the presence of increasing competition in the political arena at the local level.

Fifth, advanced communication infrastructures do not influence the start up of egovernment but do affect e-government intensity. The only context specific factor that seems to impact significantly on innovation within, rather than on innovation between, municipalities is the diffusion of broadband in the area in which they are located (see coefficient of BroadBand Share in column 6 of Table 2). The presence of broadband infrastructures does not seem to affect significantly the decision to start up the digitalization of public services. At this stage the objective of municipalities is the presence on the web of relatively simple applications and services such as information services (e.g. basic tourist information and guidance to the citizen on administrative procedures) and communication services (e.g. self-managed webspaces to be used by associations and organizations, links to other public administration sites, discussion fora). On the other hand, broadband connections become essential when the $e$ government service supply is richer (in terms of the number of services provided) and more articulated (in terms of interactivity levels and technologically complex).

Sixth, the decision to enter e-government activities is associated with a narrower range of generally less complex internal capabilities than those needed to increase the intensity of digitalised services. Differences in innovation between municipalities are 
not affected by the number of workers with experience in ICT nor by the efforts made to train existing workers. Increasing the range and quality of services is associated instead with a much wider set of more complex competencies (see OLS specification in the last column of Table 2).

\section{Conclusions}

Using evidence on 1,176 municipalities in Italy, and combining several datasets on the characteristics of local PAs and of the territory in which they are located, we evaluated different factors associated with the development of e-government services.

In more general terms, the combination of internal competencies and context specific factors is different when explaining the decision to start e-government activities $v s$. the intensity of such activities. Regional factors concerning both the demand and the supply of services appear to affect only the decision to enter egovernment activities. Competencies needed to expand and improve the quality of services are much more numerous and complex than the ones associated with the mere decision to start e-government activities.

The examined evidence is consistent with a view of e-government development as a process of gradual, step by step involvement, wherein municipalities initially engage in exploratory activities, favoured by an external context conducive to innovation and by very limited internal competencies. Once more efforts are made to expand and improve services supplied, more qualified competencies and more advanced environmental conditions need to be created. There is no guarantee that such circumstances occur, so that further development of currently embryonic egovernment is at risk. This calls for increasing investments in training, human capital formation and in hardware and software devices at the individual municipality level. It also requires greater efforts to improve the technological environment in which PAs are active, including investments to improve the quality and accessibility of digital communications networks.

\section{References}

1. Tung, L.L., Rieck, O.: Adoption of electronic government services among business organizations in Singapore. Journal of Strategic Information Systems 14, 417-440 (2005)

2. Caldas, A., David P., Ormanidhi O.: Digital Information Network Technologies, Organisational Performance and Productivity. An Exploratory Study of the Public Sector in Europe. The Oxford Internet Institute, Oxford (2005)

3. Torres, L., Pina, V., Acerete, B.: E-Government developments on delivering public services among EU cities. Government Information Quarterly 22, 217-238 (2005)

4. Nelson, R.R.: Recent evolutionary theorising about economic change. Journal of Economic Literature XXXIII, 48-90 (1995)

5. Barras, R.: Towards a theory of innovation in services. Research Policy 15, 161-173 (1986)

6. Andersen, B., Howells, J., Hull, R., Miles, I., Roberts, J. (eds.): Knowledge and Innovation in the New Service Economy. Edward Elgar, Cheltenham (2000) 
7. Clark, J., Good, B., Simmonds, P.: Innovation in the Public and Third Sectors. National Endowment for Science, Technology and the Arts (NESTA). Innovation Index Working Paper, London (2008)

8. Nelson, R.R., Winter, S.G.: An Evolutionary Theory of Economic Change. Belknap Press of Harvard University Press, Boston, MA (1982)

9. Antonelli, C.: Diffusion as a process of creative adoption. Journal of Technology Transfer 31, 211-226 (2006)

10. Schmookler, J.: Economic sources of inventive activity. Journal of Economic History, 120 (1962)

11. Schmookler, J.: Invention and Economic Growth. Harvard University Press, Cambridge (1966)

12. Scherer, F.M.: Demand-pull and technological innovation: Schmookler revisited. Journal of industrial economics 30, 225-237 (1982)

13. Mowery, D.C., Rosenberg, N.: The influence of market demand upon innovation: a critical review of some recent empirical studies. Research Policy 8(1979), 102-153 (1979)

14. Brouwer, E., Kleinknecht, A.: Innovative output, and a firm's propensity to patent. An exploration of CIS micro data. Research Policy 28(6), 615-624 (1999)

15. Gallouj, F., Weinstein, O.: Innovation in services. Research Policy 26, 537-556 (1997)

16. Miles, I.: Innovation in services. In: Fagerberg, J., Mowery, D.C., Nelson, R. (eds.) The Oxford Handbook of Innovation, Oxford University Press, Oxford (2005)

17. Zanfei, A.: Domanda pubblica e innovazione nelle telecomunicazioni in una fase di trasformazione tecnologica e istituzionale. Quaderni di ricerca IEFE-Università Bocconi, Milano (1998)

18. Edquist, C., Hommen, L., Tsipouri, L.: Public Technology Procurement and Innovation. Kluwer Academic Publishers, Dordrecht (2000)

19. Lundvall, B.A.: National Systems of Innovation: Towards a Theory of Innovation and Interactive Learning. Pinter Publishers, London (1992)

20. Edquist, C.: Systems of innovation. Perspectives and challenges. In: Fagerberg, J., Mowery, D.C., Nelson, R. (eds.) The Oxford Handbook of Innovation, Oxford University Press, Oxford (2005)

21. Saxenian, A.: Regional Advantage: Culture and Competition in Silicon Valley and Route, vol. 128. Harvard University Press, Cambridge (1994)

22. Baptista, R.: Geographical clusters and innovation diffusion. Technological Forecasting and Social Change 66, 31-46 (2001)

23. Asheim, B., Gertler, M.: The geography of innovation: regional innovation systems. In: Fagerberg, J., Mowery, D.C., Nelson, R.R. (eds.) The Oxford Handbook of Innovation. Oxford University Press, Oxford (2005)

24. Capgemini.: On line Availability of Public Services: How Is Europe Progressing? Web based survey on electronic public services. Report of the 6th measurement, Bruxelles (2006)

25. Capgemini.: The User Challenge. Benchmarking The Supply Of Online Public Services. Report of the 7th measurement, Bruxelles (2007)

26. Glaeser, E.L.: Learning in cities. Journal of Urban Economics 46, 254-277 (1999)

27. Grubesic, T.H., Murray, A.T.: Waiting for broadband: local competition and the spatial distribution of advanced telecommunication services in the United States. A Journal of Urban and Regional Policy 35(2), 139-165 (2004)

28. Bresnahan, T.F., Brynjolfsson, E., Hitt, L.M.: Information technology, workplace organization, and the demand for skilled labour: firm-level evidence. Quarterly Journal of Economics 117, 339-376 (2002)

29. Wooldridge, J.M.: Econometric Analysis of Cross Section and Panel Data. The MIT Press, Cambridge (2001) 